\title{
Socio-demographic and Clinical Characteristics of patients with Thyroid Disorders in Erbil Governorate/Iraq Bahjat AhmadMohamadAl Barzanji (MSc) ${ }^{1}$, Ibrahim Hasan Mustafa $(\mathrm{PhD})^{2}$ and Kareem Fattah Aziz $(\mathrm{PhD})^{3}$
}

\begin{abstract}
\end{abstract}
Background: Thyroid disorder is one of the commonest disorder worldwide and also in Iraq. Objective: To study identify clinical presentations of thyroid disorder and its distribution in the terms of sex, age and residency. Classifying the patients who underwent operations according to types of the disease and complications were event after operations in Erbil Governorate.

Patients and Methods: A retrospective study carried out in Hawler Teaching Hospital Out patients Clinic and privet clinic, from January 2014 to December 2018.Study involved 800 patients with goiter disordered who attended to hospital or private clinic. Data gathered by questionnaire which involved patients' socio-demographics data, signs and symptoms, clinical features of disorder, medical and surgical treatment offered to those patients, and the reports of complications' incidence that event in postoperative. Data were analyzed by the statistical package for the social science (SPSS, version 22) was used for data entry and analysis. Frequency and Percentages were used to identify distribution the disease, types, and complications.

Results: There was high frequency of disorders among female $710(88.7 \%)$ and adults, inconsistency of diseases' signs and symptoms among patients, highest percentage (44.2\%) of patients were multinodular goiter, near to half of patients 392(49\%) underwent operation and complications were reported with $42(10.7 \%)$ of patients after surgical operations.

Conclusion: The proportion of female is high, there was high proportion of patients who needed to surgical treatment and there was proportion of patients with complications after surgical operations.

Keywords:Thyroid disorders,Signs and symptoms,Underwent operation,Complication, Erbil Corresponding Author: drkareem2009@yahoo.com

Received: $25^{\text {th }}$ February 2019

Accepted: $27^{\text {th }}$ May 2019

${ }^{1,2,3}$ College of Nursing- Hawler Medical University- Erbil- Iraq.

\section{Introduction}

The thyroid gland is one of endocrine gland which is located in the lower front of the neck below the larynx. The gland's function is to produce thyroid hormones in the blood. These hormones are useful in the body for regulate body temperature, 
metabolism, heart rate, and keep the brain , heart, muscles, and other organs to work in efficiently[1].Disorder of thyroid gland is effect on body health specially weight, brain chemistry (may be develop depression or anxiety), energy level and heart problems [2]. The thyroid diseases are one of the common diseases because it's prevalent is high around the world.(3,4).It was estimated as 200 million people worldwide have iodine diet deficiency. In the United States in each year there was 360.000 new cases of hyperthyroidism, and $1.8 \%$ of them takes thyroid replacement medication to treat hypothyroidism [5,6]. According to study carried out in Colorado. Sample involved 25000 persons. Results indicated $6 \%$ of sample who was age between 20 and 70 years were taking thyroid hormone [7].A study carried out by Ogbera and Kuku in year 2011. Study depended on all available articles related to thyroid disorders which carried out in African continent and published until May 2011. Results showed that the iodine deficiency disorder is the commonest reason of thyroid disorders in Africa in addition the results found that the prevalence of endemic goiter range from 1 to $90 \%$ in this continent [8].A Systematic review study carried out by Shahrani et al 2016. Study involved 21 articles, from different Arab regions. The results indicated that there was diversity in type and prevalence of thyroid diseases in Arab countries, ranging from 6.18 to $47.34 \%$, the prevalence of goiter in number of articles carried out in Egypt, Algeria, and Bahrain were $25.25,86$, and 1.7 respectively[9].

The disorders of thyroid gland commonly present as derangement of thyroid hormone, producing, thyroid enlargement or pain. The disorder is diverse includes hypothyroidism, hyperthyroidism, simple nodular enlargement, neoplastic enlargement and thyroiditis. The abnormalities may occur which includes lingual thyroid, absence or hypoplasia. The spectrum of thyroid enlargements includes solitary thyroid nodules which develop a cysts, adenomas, malignancy and the non toxic Multi-Nodular Goiter (MNG) [10,11]. The thyroid diseases accurse in both sexes but female more likely to develop problem than male, in addition women during the pregnancy have the risk of thyroid disorder more than other time, and the age also play important role in developing thyroid diseases [12].Up to researchers' knowledge, no previous study had been carried out in the Erbil to study the distribution of thyroid disorder, underwent surgical operation patients and post operative complications. The study aimed to identify clinical presentation of thyroid disorder and distribution the diseases according to terms of sex, age and residency. Classifying the patients who underwent operations according to types of the disease and complications were event after operations inErbil Governorate.

\section{Patients and Methods}

A retrospective study carried out in outpatients' clinic of Hawler Teaching Hospital and privet clinic, from January 2015 
to February 2019. This study was approved by the Ethical Committee of College of Nursing Hawler Medical University. The participants in the study were informed about the reason of research in a simple understandable language.

Study involved 800 patients with confirmed thyroid diseases by decision of clinical medical staff and seen at the both places (Out patients' clinic and private clinic) during study period.

\section{Statistical analysis}

Data gathered by special questionnaire which involved some patients' sociodemographics data (such as age, sex, and residency), signs and symptoms of disease, past medical history of disease, clinical features for disorder (included patients thyroids' shapes and consistencies),medical and surgical treatment offered to those patients, reports of complications' incidence that event in postoperative.

\section{Results}

Study show that the mean and $( \pm \mathrm{SD})$ of age of patients was $35.79 \pm 12.9$.The majority $(88.7 \%)$ of study sample were female the ratio of male to female was $0.1: 1$.

Regarding the age of patients results show that $58.5 \%$ of study sample patients' age between 21 to 40 years, followed by $19 \%$ of patients' age between 41 to 50 years. The results also show that $11.3 \%$ of patients' age equal and less than 20 years Table (1). Regarding residency of patients results show that the highest percentage $36.6 \%$ of study sample were patients from Erbil center, and $24.8 \%$ of sample were patients from Shaqllaw distract and the lowest percentage of sample $15.8 \%$ patients from Choman distract Table (1).

Table (1): Distribution the study sample according to sex, age and residency.

\begin{tabular}{|l||c||c||}
\hline Variables & Frequency & Percentage \\
\hline \hline Sex & & \\
Male & 90 & 11.3 \\
Female & 710 & 88.7 \\
\hline \hline Age & & \\
$<20$ & 90 & 11.3 \\
$21-30$ & 228 & 28.5 \\
$31-40$ & 240 & 30.0 \\
$41-50$ & 152 & 19.0 \\
$51-60$ & 57 & 7.1 \\
$61+$ & 33 & 4.1 \\
\hline Residency & & \\
Erbil city & 293 & 36.6 \\
Soran & 182 & 22.8 \\
Shaqllaw & 198 & 24.8 \\
Choman & 127 & 15.8 \\
\hline \hline Total & $\mathbf{8 0 0}$ & $\mathbf{1 0 0}$ \\
\hline
\end{tabular}

Present study shows that patients who were and heat intolerance consisted 35.9, 32.1, and suffered from weight loss, loss of appetite, $31.4 \%$ respectively. Results also show that 
patients who were increased the appetite, and weight gained consisted $27.5 \%$ and $26.5 \%$ respectively. The results also show that the patients who suffered from difficulty in swallowing, cold intolerance, and dyspnea were harvested $19.0 \%, 15.4 \%$, and $14.4 \%$ of respectively. Same results show that one fifth $(20.6 \%)$ of sample has positive family history about disease Table(2).

Table (1): Distribution the patients according to signs and symptoms and past medical history.

\begin{tabular}{|c|c|c|c|c|}
\hline \multirow{2}{*}{$\begin{array}{l}\text { Variables } \\
\text { Signs and symptoms* }\end{array}$} & \multicolumn{2}{|c|}{ Appearance } & \multicolumn{2}{|c|}{ Not Appearance } \\
\hline & Frequency & $\%$ & Frequency & $\%$ \\
\hline Loss of appetite & 257 & 32.1 & 543 & 67.9 \\
\hline Increase of appetite & 220 & 27.5 & 580 & 72.5 \\
\hline Weight gain & 212 & 26.5 & 588 & 73.5 \\
\hline Weight loss & 287 & 35.9 & 513 & 64.1 \\
\hline Pifficulty in swallowing & 152 & 19.0 & 549 & 81.0 \\
\hline Heat intolerance & 251 & 31.4 & 549 & 68.6 \\
\hline Cold intolerance & 123 & 15.4 & 677 & 84.6 \\
\hline Dyspnea & 115 & 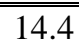 & 685 & 85.6 \\
\hline \multicolumn{5}{|l|}{ Past medical history } \\
\hline Positive & 635 & 20.6 & & \\
\hline Negative & 165 & 79.4 & & \\
\hline Total & 800 & 100 & & \\
\hline
\end{tabular}

*The total and percentages of appearance and not appearance of signs and symptomsequal 800(100\%) in raw.

Present study shows that the highest percentage 40.0 of sample was patients with diffuse shape thyroid gland followed by $31.3 \%$ were patients with nodular shape. Regarding palpation of patients results found that near to half $(50.5 \%)$ of patients in the sample were firm, followed by $37.3 \%$ were patients with soft and less than $5 \%(4.4 \%)$ were patients with fixed Table (3).

Table (3): Distribution the disease according to inspection and palpation.

\begin{tabular}{||l||c||c|}
\hline Variables & $\begin{array}{c}\text { Frequency } \\
\mathbf{8 0 0}\end{array}$ & $\begin{array}{c}\mathbf{\%} \\
\mathbf{1 0 0}\end{array}$ \\
\hline \hline Shape of thyroid gland & & \\
\hline \hline Diffuse & 320 & 40.0 \\
\hline Nodular & 250 & 31.3 \\
\hline Nodule & 140 & 17.5 \\
\hline \hline Not enlarged & 90 & 11.2 \\
\hline \hline Consistency & & \\
\hline \hline Soft & 298 & 37.3 \\
\hline \hline Firm & 404 & 50.5 \\
\hline Hard & 14 & 1.8 \\
\hline \hline Cystic & 48 & 6.0 \\
\hline \hline Fixed & 36 & 4.4 \\
\hline \hline
\end{tabular}


Results show that near to half $392(49.0 \%)$ of sample were patients underwent to surgery, among them $44.2 \%$ patients with Multi-nodular goiter, followed by $19.1 \%$ were Diffuse colloid goiter patients, Benign Colloid Nodul consisted $14.0 \%$ of patients. Table (4).

Table (4): Distribution the patients according to underwent surgery and post operative complication.

\begin{tabular}{|l||c|c|}
\hline Variables & Frequency & \% \\
\hline \hline Type & & 44.2 \\
\hline MNG* & 173 & 19.1 \\
\hline \hline Diffuse colloid goiter & 75 & 2.3 \\
\hline \hline Graves' disease & 9 & 1.8 \\
\hline Toxic Thyroid Nodule & 18 & 4.6 \\
\hline Toxic MNG & 8 & 2.0 \\
\hline SubacuteThyroidits & 4 & 1.0 \\
\hline HashimotousThyroidits & 55 & 14.0 \\
\hline \hline Benign Colloid Nodule & 15 & 4.0 \\
\hline Benign Cystic Nodule & 8 & 2.0 \\
\hline \hline Follicular Carcinoma & 4 & 1.0 \\
\hline \hline Papillary Carcinoma & 16 & 4.0 \\
\hline Recurrent MNG & $\mathbf{3 9 2}$ & $\mathbf{1 0 0}$ \\
\hline \hline Total & & \\
\hline \hline Complication & 23 & 54.8 \\
\hline \hline Transient change in voice & 9 & 21.4 \\
\hline Wound haematoma & 4 & 9.6 \\
\hline Wound sepsis & 3 & 7.1 \\
\hline Transient tetany & 3 & 7.1 \\
\hline Nerve injury & $\mathbf{4 2}$ & $\mathbf{1 0 0}$ \\
\hline \hline Total & & \\
\hline
\end{tabular}

* MultinodularGoiter

Regarding complication after operative surgery results show that the complication occurred with $42(10.7 \%)$ of underwent surgery patients, among them transient change in voice occurred in occurred in $23(54.8 \%)$ of patients, followed by $9(21.4 \%)$ developed wound haematoma and the lowest percentages were Transient tetany and Nerve injury in 7.1 and $7.1 \%$ respectivelyTable(4).

\section{Discussion}

Results of present study show that the disease was more among female and adult (age 20-40). Study of Khattak et al carried out in Iran, Peshawar in year 2001. Sample involved 25237thyroid patient from 1984 to 1990. Results found that the prevailed of disease were more among adults and female [11]. Majority of sample were from Erbil which is expected because Erbil center were largest city in Erbil Governorate and residence of Erbil center is consist $59.4 \%$ of whole residence of Erbil Governorate [13]. While it's noticeable that patients from Shaqllaw consisted near to quarter which is considerable proportion. 
Regarding signs and symptoms of disease among patients present study found that appearance of signs and symptomswere not clear and not constant among all patients, in addition highest percentages of patients went for not appearance in all signs and symptoms. Weight loss, loss of appetite and heat intolerance respectively highest sign and symptoms were recorded among patients Study Al-Bustany conducted in Erbil 2011. Sample involved 675 patients. Results indicated that weight loss with increase appetite and palpation are the most common symptoms. Regarding the signs same study found tremor and wide pulse pressure are the commonest [14].

Study of El-Shfie indicated inconstancies between patients and text books regarding signs and symptoms of hypothyroidism, in addition there was uncommon symptoms appears among some patients [15]. The inconstant of signs and symptoms may be related to the differences among physicians to found the signs and symptoms even the symptoms are subjective data and its levels aredifferent from patients to others.

Around on fifth of sample was positive family history regarding thyroid disorders. Study of Manaji et al indicated that there was an evidence of interaction between history of family and other environmental factors for developing the disease [16].

Diffuse shape thyroid disorder is common among patients of present study. Thyroid nodules are the communist in women and older population according to study
ofPopoveniuc and Jonklaas in year 2013 [17].

Patients with Firm and soft palpation thyroid gland harvested majority in sample of present study. The palpations indicators is not same for all patients but usually soft is indicate for Graves disease, firm is in Hashimoto's and Quervain thyroid, Hard for malignancy, and tender is indicter for Thyroiditis [18].

Close to half of patients in the present study was underwent surgery, among them, 44.2\% of patients were with Multinodular Goiter type of thyroid disorder.

This study show the commonest complications after thyroid surgeries were transient change in the patients voices, and wound hematoma. A retrospective study conducted in Henan Tumor by $\mathrm{Du}$ et al in year 2012. Sample involved 137 consecutive patients who underwent surgical therapy. Results indicated that the most common complications were Recuurent Laryngeal Nerve (RLN) injury and symptomatic hypoparathyroidism, followed by incision site infections, bleeding, and infection. Same study also found lower complications of thyroid surgeries wereappeared with increase knowledge of surgeon about anatomy and high level of surgeons' experiences and skills about surgical treatment. In the same time results of that study found more complication occurs with extensive surgery [19]. A study carried out in Vakif Gureba Hospital, general surgical department study involved 332 patients underwent thyroid surgeries between years 2004 to 2008. Those patients were 
retrospectively evaluated to identify post operation complications. Results found in surgery lasting more than 90 minutes the risk of permanent recurrent larynex nerve injury was high, daily drainage more than $50 \mathrm{cc}$ increase the risk of seroma formation, retrosternal goiter surgery have higher risk for bleeding. The flap edema rates were high found in the operations made by resident surgeon and patient size with 3 to 4 thyroid glands [20].

\section{Conclusions}

Study concluded that the frequency of female and adults were more to developing thyroid disorders. More to one fifth of patients have past family history about the disease. There was diversity among patients about presenting signs and symptoms of disease. There was high percentage of patients who underwent surgery. Also there was some of complication event in post operative surgery among some of the patients.

\section{References}

[1]Unnikrishnan AG, Menon UV. Thyroid disorders in India: An epidemiological perspective. Indian $\mathrm{J}$ EndocrinolMetab 2011;15:S78-81.

[2]Shomon M. risk factors, signs, and symptoms, of thyroid condition. 2018. Available from:

https://www.verywellhealth.com/thyroiddisease-causes-4013368. [Accessed in Jan. 24,2019].

[3]American Thyroid Association. Hyperthyroidism. 2013.
content/uploads/patients/brochures/Hypothyr oidism_web_booklet.pdf. [Accessed in Jan. 24, 2019].

[4]Salami BA.,Odusan O., Ebili H., AkintolaP.Spectrum and prevelance of thyroid disease seen at a teriary health facility in Sagmau, South -West Nigeria. Nigerian Postgraduate Medical Journal. 2016; 23(3):137-140.

[5]Arebelle JE. Porath A. Practice guidelines for detection and management of thyroid dysfunction: a comparative review of the recommendations. Clin Endocrinal (Oxf). 2009;51:11-18.

[6] Hill AG, Mwangi I, WaganaL.,m thyroid disease in a rural Kenyan hospital. East Afr Med J 2004; 81: 631-3.

[7] Ecker JL, Musci TJ. Treatment of thyroid disease in pregnancy.ObstetGynecolClin North Am. 2007; 24:575-589.

[8] Ogbera AO., Kuku SF. Epidemiology of thyroid diseases in Africa .Indian $J$ EndocrinolMetab. 2011 Jul;15(Suppl 2):S828. doi: 10.4103/2230-8210.83331.

[9]Al Shahrani AS., El-Metwally A., AlSurimi K., Salih S., Saleh Y., Al-Shehri A. The epidemiology of thyroid diseases in the Arab world: A systematic review. Journal of Public Health Epidemiology, 2016; 8(2)1726.

[10]Flynn RW, MacDonald TM, Morris DA, Jung RT, Leese GP. The tyyroid epidemiology, audit and research study: thyroid dysfunction in the general population. J ClinEndocrinolMetab 2004; 89: 3869-084.

Available:https://www.thyroid.org/wp- 
[11]Khattak KN., Akhter S., Khan A., Siddiqui M., Nawab G. distribution of thyroid patients between age groups, sex and seasons in thyroid patients referred to Irnum Peshawar. Journal of Medical Science 2001; 1(6): 400-3.

[12] Ecker JL, Musci TJ. Treatment of thyroid diseases in pregnancy.ObstetGynecolClin North Am. 2007; 24:575-589.

[13] International -Agency Information and Analysis Unit. Erbil Governorate Profile.2010.Availablefrom:https://reliefweb. int/sites/reliefweb.int/files/resources/E429A B404C03E1E0C12577EB004EBC48Full_Re port.pdf.cited in Jan, 25, 2019.

[14] Al-Bustany. Clinical study of cases with hyperthyroidism in Erbil Governorate, Kurdistan Region- Iraq.Zanco Journal for Medical Science. 15(1):6-12.

[15] El-Shfie KT. Clinical presentation of hypothyroidism. Jounal of family and community medicine. 2003; 10(1):55-58. [16] Manji N., Carr-Smith JD., Boelaert K., Allahabadia A., Armitage M., Chatterjee VK. influences of age, gender, smoking, and family history on autoimmune Thyroid Disease phenotype. A Journal of clinical endocrinolology and metabolic. 2006; 91(12):4873-80.

[17]Popoveniuc G., Jonklaas J. Thyroid nodules. Med. Clinic. North American. 2012; 96(2):329-49.

[18]Evidence-based medical consult. Thyroid gland palpation: physical exam. Last reviewed2015.Availablefrom:https://www.eb mconsult.com/articles/physical-exam-
thyroid-gland-palpation.[Accessed in Jan. 27, 2019].

[19] Du W., Liu S., Li P., Sun L., Zhao M., Q1 J. Intra- and postoperative complications in 137 cases of giant thyroid gland tumor. Onocology letter jurnal. 2012; 4(5):965-9. [20] Celik A., Erdem H., Guzey D., Celebi F., Celik A., Birol S., Kaplan R. the factors related with postoperative complications in Begin nodular thyroid surgery. Indian Journal Surgery. 2011; 73(1):32-6. 